\title{
Bone Morphogenic Protein Type 2 Receptor Mutation-Independent Mechanisms of Disrupted Bone Morphogenetic Protein Signaling in Idiopathic Pulmonary Arterial Hypertension
}

\author{
Jarrod W. Barnes ${ }^{1}$, Elif T. Kucera ${ }^{1}$, Liping Tian ${ }^{1}$, Noël E. Mellor ${ }^{1}$, Nina Dvorina ${ }^{2}$, William W. Baldwin $I I I^{2}$, \\ Micheala A. Aldred ${ }^{3}$, Carol F. Farver ${ }^{4}$, Suzy A. A. Comhair ${ }^{1}$, Metin Aytekin ${ }^{1,5}$, and Raed A. Dweik ${ }^{1,6}$ \\ Departments of ${ }^{1}$ Pathobiology and ${ }^{6}$ Pulmonary and Critical Care Medicine, Respiratory Institute, ${ }^{2}$ Immunology, and ${ }^{4}$ Pathology, \\ and ${ }^{3}$ Genomic Medicine Institute, Cleveland Clinic, Cleveland, Ohio; and ${ }^{5}$ Department of Medical Biology, Faculty of Medicine, Erciyes \\ University, Kayseri, Turkey
}

ORCID ID: 0000-0002-4425-1288 (R.A.D.).

\begin{abstract}
Altered bone morphogenic protein (BMP) signaling, independent of BMPR2 mutations, can result in idiopathic pulmonary arterial hypertension (IPAH). Glucose dysregulation can regulate multiple processes in IPAH. However, the role of glucose in BMP antagonist expression in IPAH has not been characterized. We hypothesized that glucose uptake regulates BMP signaling through stimulation of BMP antagonist expression in IPAH. Using human plasma, lung tissue, and primary pulmonary arterial smooth muscle cells (PASMCs), we examined the protein expression of BMP2, BMP-regulated Smads, and Smurf-1 in patients with IPAH and control subjects. Gremlin-1 levels were elevated in patients with IPAH compared with control subjects, whereas expression of BMP2 was not different. We demonstrate increased Smad polyubiquitination in IPAH lung tissue and PASMCs that was further enhanced with proteasomal inhibition. Examination of the Smad ubiquitin-ligase, Smurf-1, showed increased protein expression in
\end{abstract}

IPAH lung tissue and localization in the smooth muscle of the pulmonary artery. Glucose dose dependently increased Smurf-1 protein expression in control PASMCs, whereas Smurf-1 in IPAH PASMCs was increased and sustained. Conversely, phosphoSmad1/5/8 levels were reduced in IPAH compared with control PASMCs at physiological glucose concentrations. Interestingly, high glucose concentrations decreased phosphorylation of Smad1/5/8 in control PASMCs. Blocking glucose uptake had opposing effects in IPAH PASMCs, and inhibition of Smurf- 1 activity resulted in partial rescue of Smad1/5/8 activation and cell migration rates. Collectively, these data suggest that BMP signaling can be regulated through BMPR2 mutation-independent mechanisms. Gremlin-1 (synonym: induced-in-high-glucose-2 protein) and Smurf-1 may function to inhibit BMP signaling as a consequence of the glucose dysregulation described in IPAH.

Keywords: idiopathic pulmonary arterial hypertension; Gremlin-1; bone morphogenetic proteins; Smurf-1

(Received in original form December 23, 2015; accepted in final form April 7, 2016)

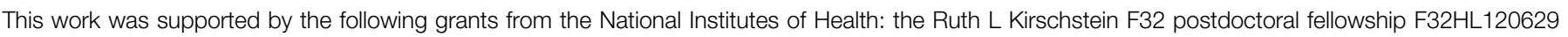
(J.W.B.) and the Programs of Excellence in Glycosciences 1P01HL10714 (R.A.D.) both from the National Heart, Lung, and Blood Institute. In addition,

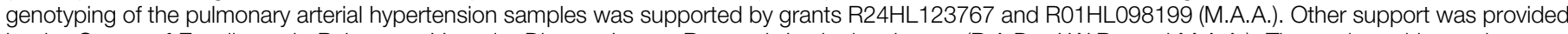

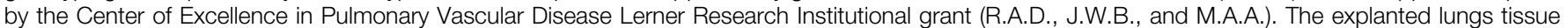

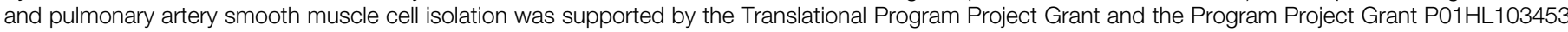
and P01HL081064, respectively (S.A.A.C. and R.A.D.). Funding for the Pulmonary Hypertension Breakthrough Initiative was provided under grant R24HL123767 and by the Cardiovascular Medical Research and Education Fund.

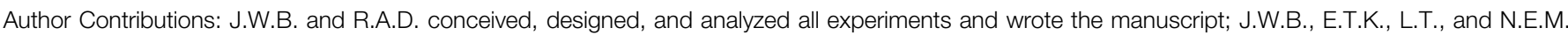
performed biochemical analyses; C.F.F. contributed tissue blocks; N.D. and W.W.B. performed immunohistochemistry and provided advice for the

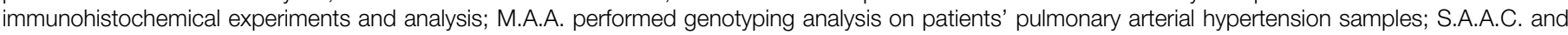
R.A.D. contributed control and idiopathic pulmonary arterial hypertension plasma, isolated cells, and explanted tissue for the project; and M.A. helped with conception, experimental design, and writing the manuscript.

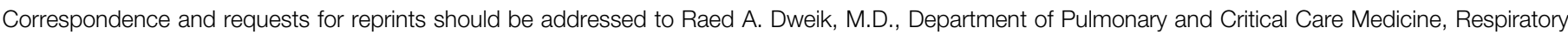
Institute, Desk A-90, Cleveland Clinic Lerner Research Institute, 9500 Euclid Avenue, Cleveland, OH 44195. E-mail: dweikr@ccf.org

Am J Respir Cell Mol Biol Vol 55, Iss 4, pp 564-575, Oct 2016

Copyright $(2) 2016$ by the American Thoracic Society

Originally Published in Press as DOI: 10.1165/rcmb.2015-0402OC on May 17, 2016

Internet address: www.atsjournals.org 


\section{Clinical Relevance}

Our data show an indirect role for Smurf-1 down-regulation of bone morphogenic protein signaling through ubiquitination of the downstream Smad effector proteins. We show that Smurf-1 is regulated by glucose and, on inhibition, results in decreased cell migration in the idiopathic pulmonary arterial hypertension pulmonary arterial smooth muscle cells similar to control migration rates. Our findings suggest that blocking Smurf-1 (and/or Gremlin-1) levels may be a plausible therapeutic strategy to inhibit the effects of increased pulmonary arterial smooth muscle cell proliferation in idiopathic pulmonary arterial hypertension.

Pulmonary arterial hypertension (PAH) is a devastating disease with multiple origins $(1,2)$. It is defined by a mean pulmonary artery pressure of $>25 \mathrm{~mm}$ $\mathrm{Hg}$ and increased pulmonary vascular resistance, which often results in right ventricular failure and premature death (3-5). PAH, which has a poor prognosis, currently affects $>100$ million people worldwide, with a higher frequency of occurrence in women than in men $(3,6-9)$. Without treatment, the $\mathrm{PAH}$ survival rate is $<3$ years. Several categories of PAH have been defined (10). A number of factors, such as environmental stimuli, drug use, and diseases such as connective tissue disorders, can result in associated PAH (10). The idiopathic form of PAH

(IPAH) is distinguished by an absence of identifiable cause. In addition, multiple gene mutations, including $A C V R L 1$, $B M P R 1 B, C A V 1, E N G, K C N K 3$, and SMAD9, have been determined to cause heritable PAH (HPAH). However, they make up only $\sim 3 \%$ of HPAH cases (11).

The heterozygous loss-of-function bone morphogenic protein type 2 receptor (BMPR2) mutations are the predominant genetic basis of HPAH (75\%) (11). These mutations attenuate the normal cellular functions of bone morphogenic proteins (BMPs) (BMP2, BMP4, and BMP9) in the lung and result in PAH (12-16). To date, more than 600 distinct BMPR2 mutations have been identified in patients with PAH (11).
It is known that a significant proportion (10-40\%) of patients who develop IPAH have the BMPR2 mutation without a known family history (17). Only a small percentage of family members with $B M P R 2$ mutations (27\% on average) develop $\mathrm{PAH}$ (18). These statistics suggest that other modes of BMP signal regulation, independent of the BMPR2 mutations, may influence and account for the development of PAH.

Antagonists of growth factors are regulatory mechanisms that control growth factor signaling and function at multiple stages. Several reports have described known antagonists of BMPs such as Gremlin-1 and Smurf-1 that regulate upstream or downstream BMP signaling events $(19,20)$. Upstream, the secreted BMP antagonist, Gremlin-1, has been shown to bind to and sequester BMPs, not allowing them to interact with the BMP receptors, thus terminating signaling events (21). In addition, Gremlin-1 has been documented to prevent BMP secretion and activation (22). Downstream, BMP signaling can be attenuated by several regulatory factors, including inhibition of Smad activation and translocation to the nucleus through Smad ubiquitin ligases known as Smurfs.

Past reports define significant roles for Gremlin-1 and Smurf-1 in the regulation of several processes, including cell differentiation and proliferation (23-26). The roles of these BMP antagonists in diseases such as diabetes, liver fibrosis, cancer, and right ventricular hypertrophy and failure demonstrate their importance in disease pathophysiology (27-30).

Currently, there is mounting evidence that altered BMP signaling may result from factors independent of $B M P R 2$ mutations in IPAH (31-34). Indeed, the modes of BMP activation and signaling must have multiples stages of regulation. The aberrant up-regulation of these BMP signaling antagonists has been suggested in IPAH, but the molecular underpinnings that govern the increase in these inhibitors are not well understood.

The aim of this report was to determine the role of excess glucose uptake on BMP signaling. Using human samples, we showed that glucose dose dependently stimulated the Smad ubiquitin ligase, Smurf-1, in control pulmonary arterial smooth muscle cells (PASMCs), whereas increased and sustained Smurf-1 protein levels in IPAH PASMCs were reduced by blocking glucose uptake. PhosphoSmad1/5/8 (p-Smad 1/5/8) levels were inversely proportional to the findings in control and IPAH under the same conditions. In addition, polyubiquitination of Smad-1 was augmented in lung tissue and IPAH PASMCs treated with a proteasomal inhibitor. Inhibition of Smurf- 1 activity resulted in a partial rescue of Smad 1/5/8 activation, together with cellular migration rates in IPAH. Collectively, this report suggests that altered BMP signaling in IPAH can result independent of BMPR2 mutation status. We put forth the notion that Smurf-1 expression is stimulated by glucose, which has been confirmed to be dysregulated in the lungs of patients with IPAH (35-39), and may trigger the degradation of BMP-regulated Smads and reduction in Smad activation. The role of glucose in the regulation of Gremlin-1 expression in IPAH is also discussed.

The study population and demographic data are listed in Table 1. Not all analyses (including BMPR2 mutation analysis) were performed on all samples because of the limitation of sample availability and consent for genetic analysis. BMPR2 mutations were identified in two subjects with a known family history of PAH (one lung tissue sample and one PASMC). No mutations were identified among six IPAH samples (four lungs, two PASMCs), or seven control samples. The number of samples in each experimental analysis is included in the text, tables, and/or figures.

\section{Materials and Methods}

\section{Lung Tissue, PASMC Isolation, and Culture Conditions}

All explanted lungs were either collected at the Cleveland Clinic through an institutional review board-approved protocol or provided by the Pulmonary Hypertension Breakthrough Initiative. Human lung tissue in this study was obtained from nine donor lung explants not suitable for lung transplant and from nine patients with PAH (Table 1). Human PASMCs were isolated from elastic pulmonary arteries dissected from both control and PAH lungs obtained at explantation (Table 1) using a previously described method (40). The PASMCs were confirmed routinely through positivity 
Table 1. Demographic Information for Human Lung Explants, Primary PASMCs, and Plasma

\begin{tabular}{lc}
\hline Sample Source & n Age Gender \\
& \\
IPAH lung tissue (n) & 9 \\
Age, yr & $38.3(14-56)$ \\
Female & $4(44.4)$ \\
PAH category & \\
Idiopathic PAH & $8(88.9)$ \\
Heritable PAH & $1(11.1)$ \\
(BMPR2 mutation) & \\
IPAH PASMCs (n) & 4 \\
Age, yr & $39.0(26-52)$ \\
Female & $3(75.0)$ \\
PAH category & $3(75.0)$ \\
Idiopathic PAH & $1(25.0)$ \\
Heritable PAH & \\
(BMPR2 mutation) & 26 \\
PAH plasma (n) & $48.5(28-76)$ \\
Age, yr & $19(73.0)$ \\
Female & \\
PAH category & $12(46.0)$ \\
Idiopathic PAH & $14(54.0)$ \\
Associated PAH & 9 \\
Control lung tissue (n) & $42.8(17-64)$ \\
Age, yr & $2(22.2)$ \\
Female & 4 \\
Control PASMCs (n) & $47.3(42-57)$ \\
Age, yr & $3(75.0)$ \\
Female & 12 \\
Control plasma (n) & $31.3(18-55)$ \\
Age, yr & $8(67.0)$ \\
Female & \\
\hline Definion of abbreviations: BMPR2, & $b 0 n e$ \\
\hline
\end{tabular}

Definition of abbreviations: BMPR2, bone morphogenic protein type 2 receptor; IPAH, idiopathic pulmonary arterial hypertension; $\mathrm{PAH}$, pulmonary arterial hypertension; PASMCS, pulmonary arterial smooth muscle cells.

Data are presented as mean (range: MIN-MAX) or No. (\%) as appropriate.

staining for $\alpha$-smooth muscle cell actin (Sigma-Aldrich, St. Louis, MO). PASMCs were used between passages 5 and 9 and were grown in low glucose $(1 \mathrm{~g} / \mathrm{L}) \mathrm{SMBM}-2$ media (Lonza, Walkersville, MD) supplemented with growth factors (Growth Factor Bullet Kit; Lonza) unless otherwise specified for experimental conditions as described (38).

\section{Mutation Analysis of BMPR2}

DNA was extracted from PASMC or RNA later-preserved lung tissue using the QIAGEN DNA Mini kit (QIAGEN, Valencia, CA) according to the manufacturer's instructions. Sequence analysis of the coding region and intron-exon boundaries of $B M P R 2$ were performed by polymerase chain reaction (PCR) amplification and Sanger sequencing, as described previously (41). Data were analyzed using Mutation
Surveyor software (Softgenetics, State College, PA). Screening for whole exon deletions and duplications was performed by multiplex ligation-dependent probe amplification using reagents from MRC Holland (Amsterdam, the Netherlands) and custom-designed oligonucleotides, as described previously (42)

\section{Complementary DNA Synthesis and Real-Time Quantitative PCR}

Real-time quantitative PCR was used to quantitatively measure the mRNA expression of Gremlin1 and BMP2 in lung tissues from healthy control subjects $(n=9)$ and patients $(n=9)$ with IPAH. Snap-frozen tissues were stored in RNA later-ICE solution. Samples were then homogenized using an OMNI THQ digital tissue homogenizer machine (OMNI International, Kennesaw, GA). Total RNA was isolated using TRIzol (Invitrogen, Grand Island, NY). RNA was measured spectrophotometrically at 260 and $280 \mathrm{~nm}$ and was reverse transcribed $(1 \mu \mathrm{g})$ in a $20 \mu \mathrm{l}$ reaction volume using oligo(dT) and M-MLV reverse transcriptase and the reaction buffer provided in the Reverse Transcription Kit (all from Promega, Madison, WI). Specific PCR primers targeted for Gremlin, BMP2, and glyceraldehyde phosphate dehydrogenase are listed in Table 2. Real-time PCR was performed with CFX96 Real-Time System (Bio-Rad, Hercules, CA). Approximately $1 \mu \mathrm{l}$ of complementary DNA was amplified in each $20 \mu$ l of PCR reaction mix containing $10 \mu \mathrm{l}$ of SYBR Green Master Mix (Applied Biosystems, Grand Island, $N Y)$. The target gene $C_{T}$ values $\left(\Delta C_{T}\right)$ and the housekeeping gene were calculated for each experimental sample. Differences in the $\Delta \mathrm{C}_{\mathrm{T}}$ values between the experimental and control samples $\left(\Delta \Delta \mathrm{C}_{\mathrm{T}}\right)$ were calculated and reported as fold change $2^{\left(-\Delta \Delta \mathrm{C}_{\mathrm{T}}\right)}$ in expression of the gene of interest between the two samples, as described previously (43).

\section{ELISA}

A human BMP2 ELISA DuoSet (R\&D Systems, Minneapolis, MN) and a human Gremlin-1 ELISA (Wuhan USCN Business Co., Ltd) were used to measure BMP2 and Gremlin-1 levels from human $\mathrm{PAH}$ $(n=29)$ and control $(n=12)$ plasma (Table 1) according to the manufacturer's recommendations. After the primary and secondary incubations, the plates were washed, and 3,3',5,5' -tetramethylbenzidine substrate mix $(1: 1)$ was added for $\sim 10-20$ minutes. The color reaction was stopped with a stop solution provided in the kit, and the optical density of each well was measured using a SPECTRAmax $\mathrm{M} 2^{\mathrm{e}}$ photospectrometer (Molecular Devices, Sunnyvale, CA) at $450 \mathrm{~nm}$ with a correction set to $570 \mathrm{~nm}$. Concentrations were reported as nanograms per microliter for both Gremlin-1 and BMP2.

\section{Lung Tissue and PASMC Preparation for Western Blots and Immunoprecipitation}

Western blotting. Lung tissue and PASMCs were prepared as described previously (38) with the addition of phosphatase inhibitors (Sigma-Aldrich) and were subjected to SDS-PAGE and Western blot analysis. Nitrocellulose membranes were probed with antisera for the following:

1. Goat anti-BMP2 (1/200; Abcam, Cambridge, MA), rabbit anti-p-SMAD 1/5/8 (1/1000; Cell Signaling, Danvers,

Table 2. List of Primers Used in RT-qPCR

Primer Name

hGremlin-1 fwd

hGremlin-1 rev

hBMP-2 fwd

hBMP-2 rev

hGAPDH fwd

hGAPDH rev
Sequence

GCAAATACCTGAAGCGAG AC
CGATGGATATGCAACGAC AC
AAACTCCTCCGTGGGATAG
CCGAGCCAACACTGTGC
ACCACAGTCCATGCCATCAC
TCCACCACCCTGTTGCTGTA

GCAAATACCTGAAGCGAG AC CGATGGATATGCAACGAC AC CCGAGCCAACACTGTGC TCCACCACCCTGTTGCTGTA
GenBank Accession Number

Definition of abbreviations: BMP, bone morphogenic protein; fwd, forward primer; rev, reverse primer; RT-qPCR, real-time quantitative polymerase chain reaction.

Shown are the names, sequences, and source sequence accession numbers used for RT-qPCR. Names of primers for human genes are preceded by the letter $h$. 
MA), and rabbit anti-SMAD 1/5/8

(1/1000; Santa Cruz Biotechnology, Inc., Dallas, TX), followed by three washes for 15 minutes with Tris-buffered saline and Tween (TBST). After incubation with respective secondary antibodies conjugated with horseradish peroxidase, blots were developed using enhanced chemiluminescence (Amersham, Pittsburgh, PA).

2. Rabbit anti-Smurf 1 (1/1000; Santa Cruz) and $\beta$-Actin (1/10,000; Santa Cruz) were blocked, washed, and imaged using an Odyssey Infrared Imaging System (Li-Cor Biosciences, Lincoln, NE). All protein densities were calculated and normalized to b-actin or p-Smad, normalized to total Smad ratios, and quantitated using ImageJ (44) software.

Immunoprecipitation for lung tissue. Snap-frozen IPAH $(n=3)$ and control $(n=3)$ lung tissues stored in RNA later were lysed in RIPA buffer containing a protease inhibitor cocktail (Sigma-Aldrich) and phosphatase inhibitors (Sigma-Aldrich), followed by homogenization on ice using an OMNI THQ digital tissue homogenizer machine (OMNI International, Kennesaw, GA). The homogenized tissue was subjected to a $4^{\circ} \mathrm{C}$ postnuclear centrifugation, and the supernatants were collected and brought to $1 \mathrm{ml}$. For PASMCs, IPAH and control cultures were grown to confluency and treated with and without MG-132, a proteasomal inhibitor, for 8 hours, followed by trypsinization and collection for immunoprecipitation (IP). To preclear lung tissue and cell supernatants, a $60-\mu \mathrm{l}$ mixed slurry of unblocked protein A/G/L sepharose (Santa Cruz) was added and they were rotated at $4^{\circ} \mathrm{C}$ for 4 hours. The sepharose beads were removed from precleared cell lysates and antisera against Smad-1 (1:200, XP RabMAb; Cell Signaling) was added for overnight IP at $4^{\circ} \mathrm{C}$. Proteinantibody complexes were purified from lysates using blocked protein A sepharose, followed by four washes using RIPA buffer, two washes with $1.0 \%$ Triton-X 100 in $20 \mathrm{mM}$ Tris $\mathrm{pH}$ 6.8, and three washes with a final wash buffer containing $20 \mathrm{mM}$ Tris- $\mathrm{HCl}$ pH 6.8. Purified protein complexes were eluded from the protein A beads by boiling in 4X Laemmli buffer (Bio-Rad) and subjected to SDS-PAGE and Western blot analysis to assess the ubiquitin modification of Smad-1 in IPAH and control samples using a rabbit anti-ubiquitin antibody (Abcam). In all cases,
$5.0 \%$ of the whole tissue lysate was set aside as a Western blot input control and probed with Smad-1 (Cell Signaling).

\section{Hematoxylin and Eosin Staining}

Tissue taken from explanted lungs was fixed and embedded in paraffin, and $4-\mu \mathrm{m}$ sections were prepared. The sections were stained with hematoxylin and eosin using standard procedures for proper lung orientation and morphological assessment. Snapshots of histology were taken using a Leica DM 5500B microscope equipped with a $4 \times$ (numerical aperture 0.10$)$ and $20 \times$ (numerical aperture 0.4 ) objective. Images were generated using an attached Leica DFC 425C camera and the highperformance Leica LAS software.

\section{Immunohistochemistry}

Human control $(n=3)$ and IPAH $(n=3)$ lung sections were deparaffinized with three xylene washes (5 min each), two $100 \%$ ethanol washes (10 min each), and two $95 \%$ ethanol washes (10 min each).

After two $\mathrm{dH}_{2} \mathrm{O}$ washes (5 min each), the lung sections were subjected to steam and $0.2 \mathrm{M} \mathrm{pH} 6.0$ citrate for 30 minutes, followed by cooling at room temperature, washes in $\mathrm{dH}_{2} 0$, and incubation in $0.3 \%$ hydrogen peroxide in $80 \%$ methanol for 20 minutes. Slides were then washed and incubated in antibody diluent (Dako North America, Inc., Carpinteria, CA) plus a mouse anti-Smurf-1 primary antibody (1:50; Abnova, Inc. Littleton, CO) for 1 hour. After washes, the slides were exposed to HRP polymer (Invitrogen) and DAB (Vector Laboratories, Burlingame, CA) and counterstained with hematoxylin II, dehydrated, cleared, and permanently mounted for viewing using the same microscope and capture software as for the hematoxylin and eosin staining.

\section{Glucose Administration/Inhibition and Smurf-1 Inhibition}

Dividing control and IPAH PASMCs at $75-80 \%$ confluency were synchronized using serum-free media for 8 hours and subjected to overnight incubation (16 h) with glucose concentrations from $4.5 \mathrm{mM}$ $(81.1 \mathrm{mg} / \mathrm{dl})$ to $30 \mathrm{mM}(540 \mathrm{mg} / \mathrm{dl})$ or glucose inhibition by 2 - deoxyglucose $(2.5,5.0$, or $10 \mathrm{mM}$; Sigma-Aldrich) or fasentin (70 $\mu \mathrm{M}$; Sigma-Aldrich), a glucose transporter 1 (GLUT1) inhibitor, at $37^{\circ} \mathrm{C}, 5.0 \% \mathrm{CO}_{2}$, and $90.0 \%$ humidity. The following day, the PASMCs were collected and prepared for SDS-PAGE and Western blot analysis. In parallel experiments, control and IPAH PASMCs were cultured with and without a BMP signal enhancer (A01 [range, 0-50 $\mu \mathrm{M}]$ ); Smurf-1 inhibitor (EMD Millipore Corp., Billerica, MA)] for 24 hours and also collected for Western blot analysis.

\section{Cell Migration Assay}

PASMCs were plated at a density of 50,000 cells in specially designed Radius Migration Assay plates (Cell Biolabs, Inc., San Diego, CA) and set up for migration experiments according to the manufacture's protocol. Briefly, the PASMCs were plated and allowed to adhere overnight with and without A01 $(50 \mu \mathrm{M})$ or 2-deoxyglucose (2-DG) (5 mM; Sigma-Aldrich) before the radial gel discs were removed. On removal of the radial discs, cell migration assays were initialized with the addition of the appropriate inhibitor, and cell images were taken using an Olympus CKX41 microscope containing a $10 \times(0.25 \mathrm{PHP})$ objective with an attached SC30 camera at 0,5 , and 10 -hour time points. The gap closure percentage was determined by calculating the area of the gap using Image) (44) software at each time point and condition, followed by normalization to the 0 hour time points for each condition.

\section{Statistical Analysis}

The statistics reported are represented as mean \pm SD and are based on independent triplicate experiments. Single comparisons were performed on independent triplicate experiments using a Student $t$ test. A comparison between groups was determined on the basis of an analysis of variance test determined from the independent triplicate experiments, whereas Tukey's post hoc test was performed for individual comparisons. A $P$ value $\leqslant 0.05$ was considered significant.

\section{Results}

\section{Elevated Plasma Gremlin-1 in IPAH Compared with Control}

Using human lung tissue and plasma samples from patients with IPAH and control subjects, Gremlin-1 levels were analyzed. Transcript analysis from human lung tissue suggests that Gremlin-1 mRNA levels are increased in subjects with $\mathrm{PAH}$ relative to control individuals (Gremlin-1 fold change $\left[\Delta \Delta \mathrm{C}_{\mathrm{T}}\right], 3.3 \pm 0.6$; IPAH to control, $P<0.01$ ) (Figure 1A). 


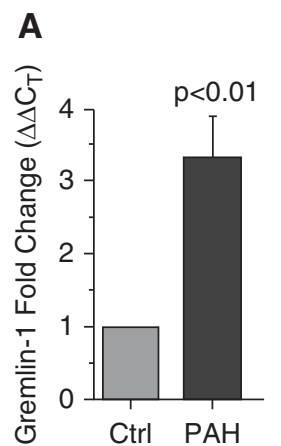

B

Figure 1. Gremlin-1 is up-regulated in human patients with pulmonary arterial hypertension (PAH). (A) Gremlin-1 mRNA expression from human control $(n=10)$ and PAH $(n=10)$ lung tissue. The target gene, Gremlin-1, was determined and compared with GAPDH in both control and $\mathrm{PAH}$ and calculated as fold change using $2^{\left(-\Delta \Delta C_{T}\right)}$. (B) PAH plasma levels of Gremlin-1 compared with control samples as determined by ELISA. Error bars represent the SDs of independent triplicate experiments. The $P$ values were given on the basis of a Student's $t$ test determined from the independent triplicate experiments. Ctrl, control.

Corresponding to mRNA expression, Gremlin-1 protein levels were increased almost two-fold in the plasma of patients with IPAH compared with that of control subjects (plasma Gremlin-1 $[\mathrm{ng} / \mathrm{ml}$, mean \pm SD]: IPAH, $0.23 \pm 0.09$; control, $0.13 \pm 0.04 ; P<0.01$ ) (Figure 1B). Collectively, these data indicate that Gremlin-1 expression is up-regulated in the lung and plasma of human patients with $\mathrm{PAH}$, which is consistent with previous reports (33).

\section{BMP2 Expression Levels in \\ Pulmonary Hypertension and Control Lungs Are Not Significantly Different}

The effects of increased BMP antagonists on the production of BMP ligands have been described; however, the role that these antagonists have on BMP expression in IPAH with no BMPR2 mutation is not well established. With this in mind, we assessed the levels of BMP2 from human plasma using ELISA and determined that the levels were not altered in patients with IPAH compared with control plasma samples (plasma BMP2 [ng/ml, mean $\pm \mathrm{SD}]: \mathrm{IPAH}$, $0.72 \pm 0.10$; control, $0.72 \pm 0.17 ; P=0.98$ ) (Figure 2A). Similarly, mRNA transcript and Western blot analysis of BMP2 from IPAH human lung tissue was no different from that of control individuals (BMP2 fold change $\left[\Delta \Delta \mathrm{C}_{\mathrm{T}}\right], 1.1 \pm 0.5$; IPAH to control, $P=0.5$ (Figure 2B); BMP2 protein expression (density, mean $\pm \mathrm{SD}$ ): IPAH, $3.8 \pm 2.3$; control, $2.5 \pm 1.2 ; P=0.65$ ] (Figure 2C), respectively). These data suggest that BMP ligand levels are unchanged in IPAH, irrespective of increased Gremlin-1 levels in the absence of a $B M P R$ mutation.

\section{A Spontaneous Molecular Weight Shift of Smad-1 in IPAH Lung Tissue Is Indicative of Polyubiquitination} Even though BMP ligand levels are unchanged, downstream effectors of BMP signaling may be altered. To determine whether $\mathrm{p}$-Smad $1 / 5 / 8$ and total Smad levels were altered, we performed Immunoblot analysis of these proteins from IPAH $(n=3)$ and control lung tissue $(n=3)$. The $\mathrm{p}$-Smad $1 / 5 / 8$ was reduced in IPAH lung tissue compared with control samples, as shown in Figure 3A (top panel). Interestingly, several higher-molecular-weight immunoreactive bands were observed (denoted by brackets) in IPAH samples
A

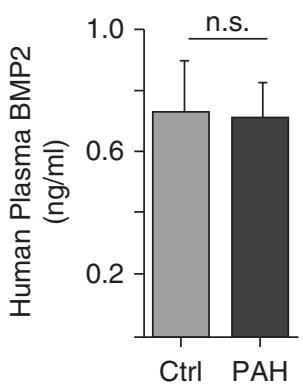

C

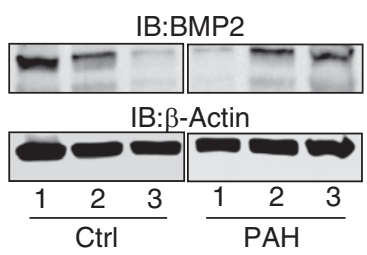

\section{B}

that were not present in the control samples. In addition, these highmolecular-weight bands were seen in the immunoblots for total Smad1 (Figure 3A, bottom panel). These data suggest that $\mathrm{p}$-Smad and total Smad levels are reduced in IPAH compared with control samples, which is most likely because of the spontaneous molecular weight shift in IPAH lung tissue samples that is not present in control samples.

Previously published reports have ubiquitinated and targeted subsequently for degradation $(45,46)$. To determine whether the total Smad levels had undergone polyubiquitination in IPAH, we performed IP for Smad1 from control and IPAH lung tissue and immunoblotted for ubiquitin. The immunopurified Smad1 from IPAH lung tissue was positive for ubiquitin modification (Figure 3B), which was not observed in control tissues under the same conditions. Collectively, these results suggest that BMP signal-regulated Smads are modified with polyubiquitin in IPAH tissue. shown that Smad proteins can be

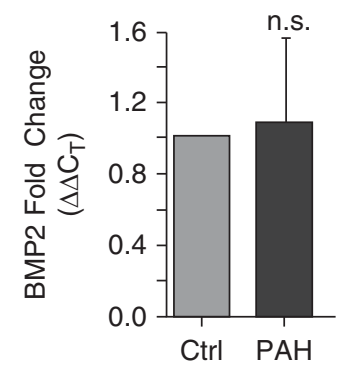

D

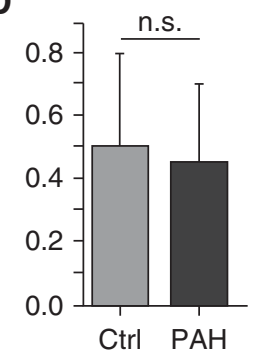

Figure 2. Bone morphogenic protein 2 (BMP2) mRNA and protein expression levels are not significantly different in patients with $\mathrm{PAH}$ (without the BMPR2 mutation) compared with control subjects. (A) BMP2 levels from human plasma were measured by ELISA. (B) mRNA fold change in expression of BMP2 in whole lung was determined as in Figure 1. (C) Western blot analysis of whole lung BMP2 protein expression in patients with PAH and control subjects. (D) Densitometry of BMP2 expression normalized to $\beta$-actin from $C$. Error bars represent the SDs of independent triplicate experiments. IB, immunoblot; n.s., not significant. 
A

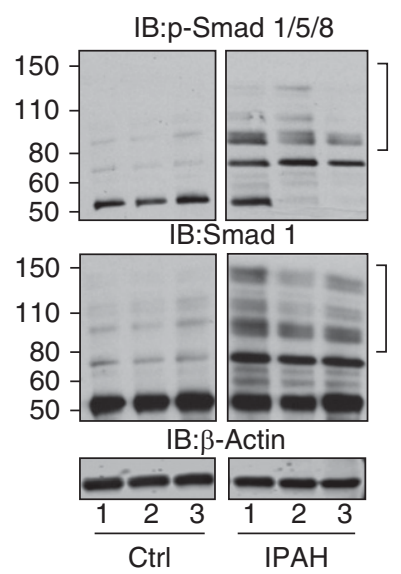

B
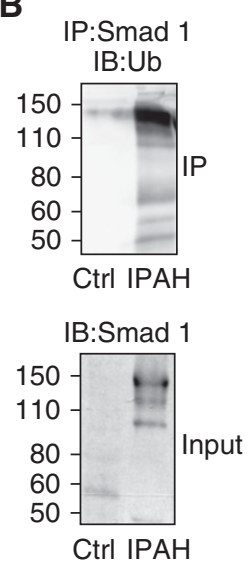

Figure 3. Idiopathic pulmonary arterial hypertension (IPAH) human lung tissue shows polyubiquitination of suppressor of mothers against decapentaplegic (Smad) proteins. The phosphorylation of Smad 1/5/8 (A, top panel) and total Smad levels ( $A$, bottom panel) determined by Western blot analysis in IPAH lung tissue compared with control tissue. (B, upper panel) Immunoprecipitation (IP) of Smad1 from human lung tissue and subsequent Western blot analysis of ubiquitin. (B, lower panel) A 5.0\% whole tissue lysate input and Western blot of Smad1. Brackets denote the observed high-molecular-weight smear in pulmonary hypertension blots. p-Smad, phospho-Smad; Ub, ubiquitin.

\section{The Ubiquitin Ligase, Smurf-1, Is Elevated in IPAH Pulmonary Vascular Smooth Muscle}

Smad proteins have been shown to be substrates for the Smad ubiquitin ligase, Smurf-1 $(47,48)$, whose expression has been observed in the lung (49). To determine whether the Smurf- 1 expression is consistent with the increased polyubiquitination of Smad-1 in IPAH, we analyzed Smurf-1 from IPAH $(n=3)$ and control $(n=3)$ lung tissues, as well as IPAH $(n=4)$ and control $(n=4)$ PASMCs. Smurf- 1 levels were significantly elevated in IPAH lung tissue compared with control tissue (Smurf [density]: IPAH, $1.32 \pm 0.43$; control, $0.55 \pm 0.20 ; P<0.05$ ) (Figures $4 \mathrm{~A}$ and $4 \mathrm{~B}$ ). In line with this, we took human IPAH $(n=3)$ and control $(n=3)$ lung tissue sections and, using immunohistochemistry (IHC), stained them for Smurf-1 (Figure 4C). The staining of Smurf-1 was localized predominantly to the smooth muscle region in the pulmonary arteries of patients with IPAH and was not stained as visibly in the control subjects. Therefore, we analyzed primary isolated smooth muscle cells from the pulmonary arteries of control subjects $(n=4)$ and patients with IPAH $(n=4)$. As shown in Figure 4D, Smurf-1 levels were significantly elevated compared with the levels in control PASMCs (Smurf-1 density: IPAH, $0.42 \pm 0.07$; control, $0.07 \pm 0.04$;
$P<0.001$ [Figure 4E]). Conversely, the phosphorylation of Smad 1/5/8 was decreased in IPAH PASMCs compared with those of control subjects, irrespective of the BMPR2 mutation ( $\mathrm{p}-\mathrm{Smad} / \mathrm{total}$ Smad ratio: IPAH, $0.09 \pm 0.07$; control, $0.80 \pm 0.36 ; P<0.001$ [Figures $4 \mathrm{D}$ and $4 \mathrm{~F}]$ ). These data indicate that Smurf-1 expression is elevated in IPAH lungs (especially in the pulmonary arterial smooth muscle) and that the phosphorylation of BMP receptor-regulated Smads is inversely proportional to the Smurf-1 levels.

\section{Smad-1 Is Polyubiquitinated at a Higher Rate in IPAH PASMCs Compared with Those of Control Subjects}

We wanted to determine whether the inverse proportionality of Smurf-1 to Smad levels was associated with Smad polyubiquitination and proteasomal degradation. Therefore, we performed an IP of Smad-1 from both control and IPAH PASMCs in the presence and absence of MG-132 (a proteasomal inhibitor). After IP of Smad-1, an immunoblot for ubiquitin was performed. As shown in Figure 4G, polyubiquitination of Smad-1 was increased in IPAH compared with control PASMCs in both the presence and the absence of MG-132. After proteasomal inhibition, the polyubiquitination of Smad-1 was augmented in both control and IPAH
PASMCs. However, the levels were increased at a higher rate in the IPAHisolated cultures. This finding is consistent with the findings of our IP experiments from the lung tissue (Figure 3). Altogether, these results suggest that Smad activation may be reduced because of increased proteasomal degradation, most likely driven by the increased Smurf-1 expression in IPAH.

\section{Glucose Levels Regulate Smurf-1 Expression and p-Smad 1/5/8 Levels in PASMCs}

It is well established that patients with IPAH exhibit more uptake of glucose and have abnormalities in glucose metabolism $(35-37,50)$. The effects of excessive or chronic glucose exposure could drastically change the cellular dynamics, resulting in altered cell proliferation, extracellular matrix remodeling, and apoptosis, all of which are regulated through BMP signaling. To determine the effects of glucose on these BMP antagonists, IPAH and control PASMCs were stimulated with a dose range of $\mathrm{D}$-glucose from physiological $(4.5 \mathrm{mM})$ to nonphysiological levels $(30 \mathrm{mM})$. As shown in Figure 5A, glucose titration resulted in a dosedependent increase of Smurf-1 in control PASMCs. Surprisingly, Smurf-1 levels in IPAH PASMCs were higher than in control PASMCs at basal levels $(4.5 \mathrm{mM})$ and were sustained even with higher glucose addition (Figures 5A and 5B). These findings were accompanied by the dose-dependent reduction in $\mathrm{p}$-Smad $1 / 5 / 8$ and total Smad in control samples that were consistently lower and opposite to the increased/sustained Smurf-1 levels in IPAH PASMCs (Figures 5A and 5B).

To determine the effects of blocking glucose uptake on Smurf-1 expression and Smad 1/5/8 activation, we treated cells with 2-DG or fasentin for 16 hours. Both 2-DG and fasentin resulted in a reduction in Smurf-1 protein expression and increased p-Smad 1/5/8 levels in IPAH (Figures 5C and 5D and Figures 5E and $5 \mathrm{~F}$, respectively), which is opposite to our findings in Figures 5A and 5B. Collectively, these data suggest that glucose regulates Smurf-1 expression, which influences Smad activation in IPAH through proteasomal degradation. These findings validate the findings of previous reports indicating metabolic abnormalities in IPAH $(37,39)$ and 

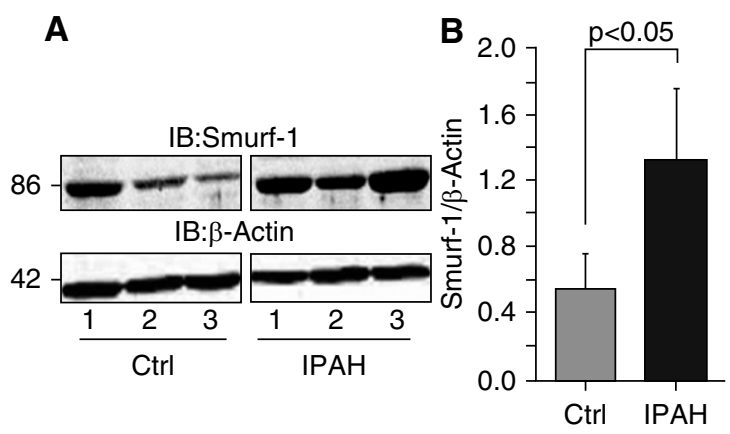

D

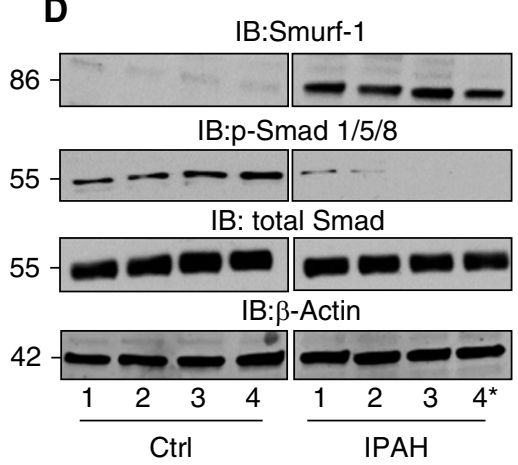

E
C

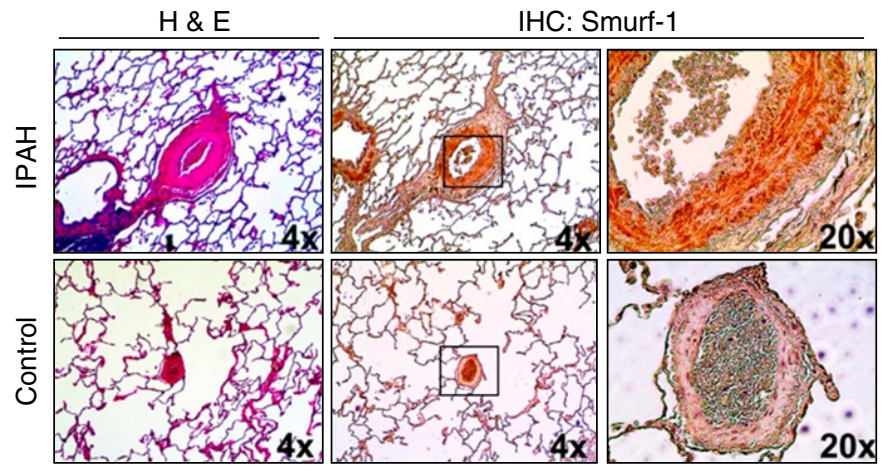

$\mathbf{F}$

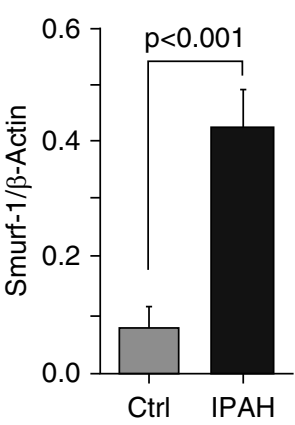

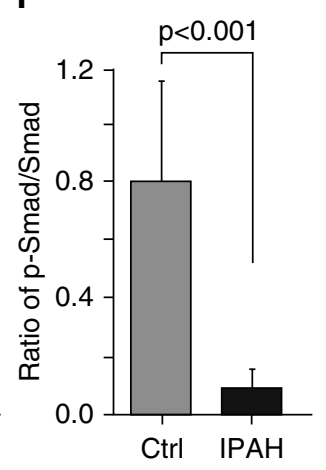

G
IP: Smad 1

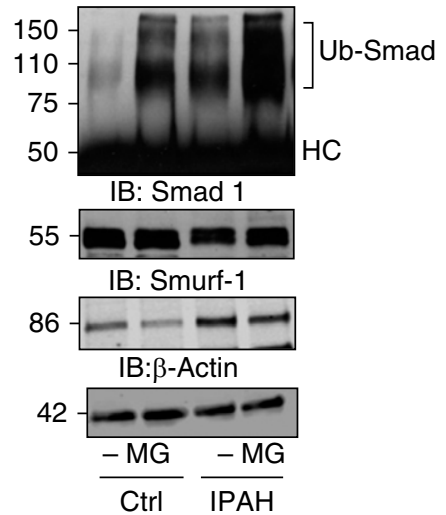

Figure 4. Smurf-1 protein is elevated in human pulmonary vascular smooth muscle, and Smad-1 is polyubiquitinated at a higher rate in IPAH pulmonary arterial smooth muscle cells (PASMCs) compared with control cells. (A) Western blot analysis of Smurf- 1 from IPAH $(n=3)$ and control $(n=3)$ lungs. $(B)$ Densitometry of Smurf-1 normalized to $\beta$-actin determined for $(A)$. $(C)$ Control $(n=3)$ and IPAH $(n=3)$ lung tissue was stained by hematoxylin and eosin (H\&E) as well as by immunohistochemistry (IHC) for Smurf-1. (D) A representative Western blot for Smurf-1, p-Smad-1/5/8, and total Smad from IPAH $(n=4)$ and control $(n=4)$ human PASMCs. ( $E$ and $F$ ) Densitometry analysis of Smurf-1 normalized to $\beta$-actin and the ratio of $p$-Smad- $1 / 5 / 8$ to total Smad determined in $(D)$, respectively. (G) PASMCs from control subjects and patients with IPAH were subjected to immunoprecipitation with Smad-1 followed by immunoblotting for ubiquitin (upper pane/) after incubation with and without the proteasomal inhibitor MG-132 (8 h). Input immunoblots of Smad-1 and Smurf-1 are also shown (middle pane/s). $\beta$-actin was used as a loading control (lower panel). Error bars represent the SDs of independent triplicate experiments. The $P$ values were based on a Student's $t$ test determined from the independent triplicate experiments. Asterisk denotes a patient with heritable PAH with a BMPR2 mutation. HC, heavy chain; MG, MG-132.

suggest an active and regulatory role for glucose on BMP signaling.

\section{Inhibition of Smurf-1 Activity Results in Decreased Cell Migration in IPAH}

A recently published report demonstrated that attenuation of Smurf-1-mediated Smad degradation resulted in enhanced BMP signaling (51). To determine the effect of blocking Smurf-1 activity on IPAH PASMC migration rates, we treated cells with and without A01, a Smurf-1 inhibitor (51), and monitored the effects on activation of Smad-1/5/8 and cell migration in IPAH (Figure 6). As shown in Figures 6A and $6 \mathrm{~B}$, the addition of A01 resulted dose dependently in an increase in Smad-1/5/8 phosphorylation in IPAH PASMCs, with little effect on control PASMCs. In line with this, the administration of A01 $(50 \mu \mathrm{M})$ to the IPAH PASMCs reduced migration and gap closure at rates similar to those determined for control PASMCs at 50- and 10-hour time points (Figures 6C and 6D). Collectively, these data suggest that inhibition of Smurf-1 by A01 augments Smad stability and activation and restores IPAH PASMC migration rates to control levels.

\section{Discussion}

In this report, we show that Smurf-1 (and Gremlin-1) may contribute to the pathogenesis of IPAH in a distinct manner, independent of BMPR2 mutation status in the disease (Figure 7). More importantly, our data demonstrate that abnormal glucose uptake and dysregulation, which have been described in IPAH, actively contribute to the stimulation of regulatory factors, including Smurf-1 and Gremlin-1, which might be responsible for the pathogenesis and/or the perpetuation of the disease.

Currently, there is mounting evidence that BMP signaling can be regulated in IPAH through BMPR2 mutationindependent mechanisms. Abnormalities in BMP receptor binding or activation of downstream BMP effector molecules may contribute to IPAH disease pathogenesis. Gremlin-1 has been shown to antagonize BMP signaling directly through intracellular and/or extracellular mechanisms, including reducing 
A

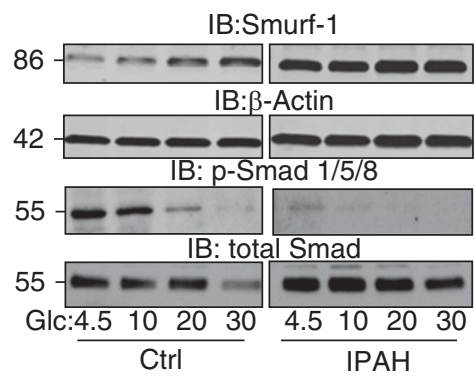

C

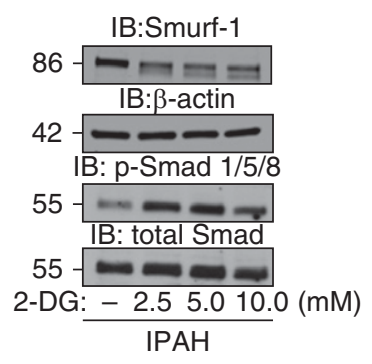

$\mathbf{E}$

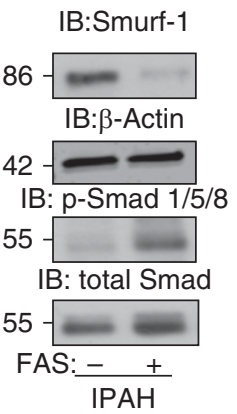

B

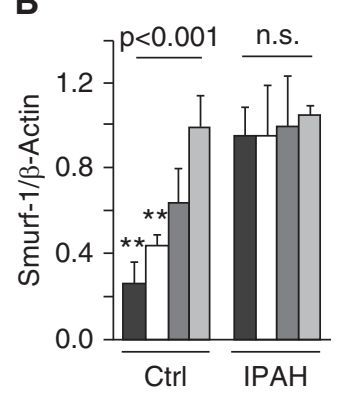

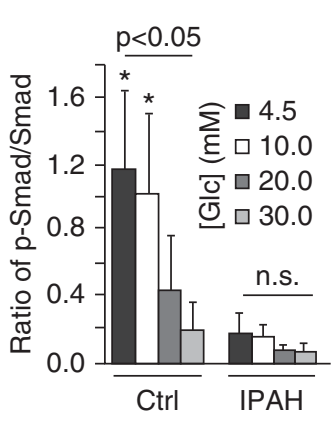
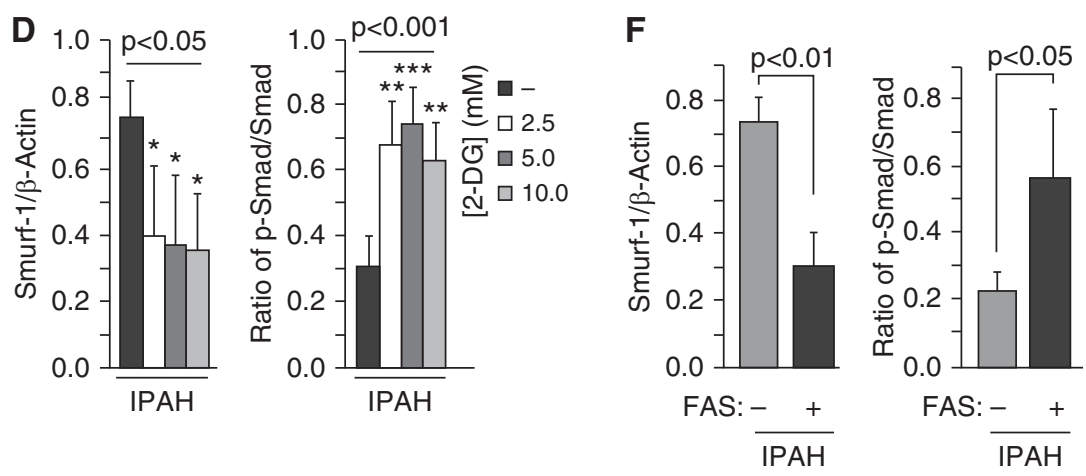

Figure 5. Glucose levels regulate Smurf-1 expression and Smad activation in IPAH PASMCs. (A) Representative Western blots of Smurf-1, p-Smad-1/5/8, and total Smad from IPAH and control PASMCs subjected to different concentrations of glucose for 24 hours. (B) Densitometry analysis of Smurf-1 normalized to $\beta$-actin and quantitation of the ratio of $\mathrm{p}$-Smad-1/5/8 to total Smad determined in $(A)$. (C) Representative Western blots of Smurf-1, p-Smad-1/5/8, and total Smad from IPAH PASMCs subjected to inhibition of glucose uptake by 2-deoxyglucose (2-DG). (D) Densitometry analysis of Smurf- 1 normalized to $\beta$-actin and quantitation of the ratio of $p$-Smad-1/5/8 to total Smad determined in $(C)$. (E) Western blots after 16 hours of fasentin (FAS) $(70 \mu \mathrm{M})$ administration into IPAH PASMC culture media. $(F)$ Densitometry of Smurf-1 normalized to $\beta$-actin and the ratio of $p$-Smad/Smad with and without FAS treatment. Error bars represent the SDs of independent triplicate experiments. The $P$ values between groups were based on an analysis of variance test determined from the independent triplicate experiments, whereas Tukey's post hoc test was performed for individual comparisons. ${ }^{\star} P<0.05 ;{ }^{\star \star} P<0.01 ;{ }^{\star \star \star} P<0.001$. Glc, glucose.

BMP/BMP receptor interactions $(52,53)$. Furthermore, regulation of BMP signaling through indirect mechanisms such as Smurf-1 ubiquitination of receptorregulated Smads has been shown (24).

Many biological functions involving Smurf-1 and Gremlin-1 inhibition of BMP signaling, including cell growth, differentiation, adhesion, and migration, have been analyzed $(23,24,34,45,46$, 51-54). These BMP antagonists have been shown to promote the proliferation of cancer cells similar to the proproliferative state demonstrated in PAH (55). On the basis of these described functions, the proposed concept whereby aberrant expression or dysfunction of Smurf-1 and/or Gremlin-1 results in disease has gained interest. Our data demonstrate that Gremlin-1 levels are elevated in PAH plasma compared with that of control subjects (Figure 1), consistent with the findings of previous reports (33). Similarly, Smurf-1 protein levels are increased in IPAH PASMCs and are localized to the pulmonary arterial smooth muscle in IPAH lung tissue (Figure $4 \mathrm{C}$ ). A reduction in the activation of Smad 1/5/8 in IPAH PASMCs was also demonstrated in three different patients with IPAH and one patient with HPAH (Figures 4D and 4F). Surprisingly, we were able to demonstrate a molecular weight shift in Smad proteins by Western blot and IP in IPAH lung tissue, which was not found in control lung tissue (Figure 3). We believe this finding to be indicative of polyubiquitination of Smad proteins by Smurf- 1 in the IPAH lung tissue (Figure 3). In line with this finding, Smad ubiquitination and proteasomal degradation was higher in IPAH PASMCs, compared with control PASMCs, after inhibition with MG-132 (Figure 4G). This result validates our initial findings in the lung tissue (Figure 3 ) and is consistent with the findings of previous reports demonstrating Smad polyubiquitination by Smurf proteins $(24,51)$. Collectively, these data show that Smurf-1 regulates BMP signaling through ubiquitination and subsequent degradation of Smad proteins in IPAH lung tissue and PASMCs, which is consistent with the reduction in Smad activation (Figures 3 and 4).

BMP signaling antagonists have been described previously in IPAH (31-34), but the mechanisms that govern the increase in these inhibitors have not been determined. Because PAH is a rapidly progressive cardiopulmonary disease, the small pulmonary arteries of patients with $\mathrm{PAH}$ are affected and the alterations originating from the pulmonary arterial dysfunction, including the aberrant vascular proliferation and remodeling, advance the disease (2-5). The role of metabolic dysfunction, in particular dysregulated glucose metabolism, on these phenotypes has been studied in IPAH $(38,50,56,57)$. In this study, a specific role for glucose on Smurf-1 expression is shown in IPAH PASMCs (Figure 5). Our data also demonstrate that glucose dose dependently stimulated the increase in Smurf-1 protein expression in control 
A

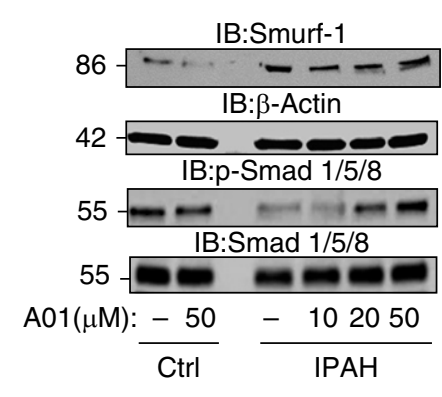

B

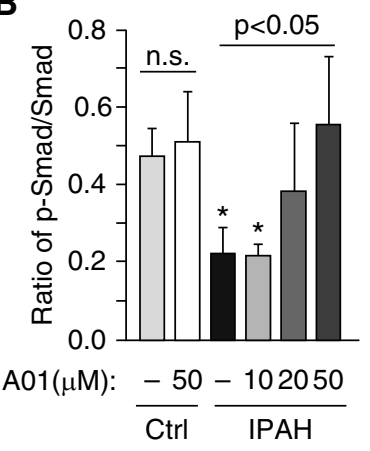

C
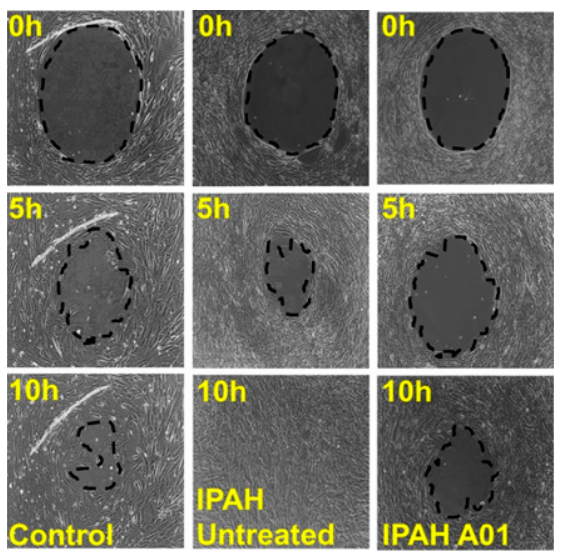

D
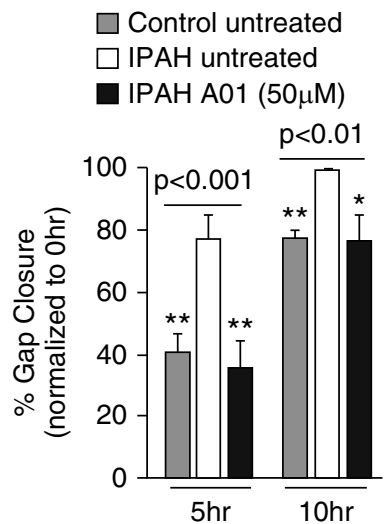

Figure 6. Inhibition of Smurf-1 activity results in increased Smad-1/5/8 activation, together with a reduction in IPAH PASMC migration rates. (A) Representative Western blots of Smurf-1, p-Smad-1/5/8, and total Smad from IPAH and control lungs subjected to different concentrations of A01, a Smurf-1 inhibitor, for 24 hours. (B) Densitometry and quantitation of the ratio of p-Smad-1/5/8 to total Smad for $(A)$. (C) Representative images of cell migration response to no treatment in control and IPAH PASMCs and IPAH PASMCs exposed to A01 at different time points. $(D)$ Graphs of the percentage gap closure from three independent experiments. Error bars represent the SDs of independent triplicate experiments. The $P$ values were based on an analysis of variance test determined from the independent triplicate experiments, whereas Tukey's post hoc test was performed for individual comparisons ${ }^{\star} P<0.05$; ${ }^{\star \star} P<0.01$.

PASMCs, whereas Smurf-1 protein levels in IPAH PASMCs were consistently increased over the concentration range (Figures $5 \mathrm{~A}$ and 5B). Partially blocking glucose uptake with 2-DG or fasentin in IPAH PASMCs resulted in decreased Smurf-1 (Figures $5 \mathrm{C}-5 \mathrm{~F})$. Under the same conditions, p-Smad1/5/8 levels were significantly reduced in IPAH compared with control PASMCs at physiological glucose concentrations, whereas dose-dependent glucose addition to control PASMCs resulted in decreased phosphorylation of Smad1/5/8 (Figures 5A and 5B). On inhibition of Smurf-1 activity in IPAH, phosphorylation of Smad 1/5/8 was partially rescued, together with cellular migration rates (Figure 6). We cannot rule out the possibility that other mechanisms driven by glucose uptake/metabolism may be involved in the process of decreased Smad activation and cell proliferation. Nevertheless, we believe that glucose dysregulation affects the IPAH PASMC proliferation rates by altering Smurf-1 expression, which regulates Smad degradation. Our data validate previously published findings on the role of Smurf-1 in IPAH (34) and also define a mechanistic and active role for glucose on Smurf-1 and its role in receptor Smad activation in IPAH.

Previous reports have shown that Gremlin-1 expression can also be stimulated by increasing glucose levels (Gremlin-1 was once termed increased-in-high-glucoseprotein-2) (58). This is consistent with the effect of glucose on Smurf-1 (Figure 5) and other ubiquitin ligases (59), as well as with the role of hyperglycemia on Gremlin-1 in podocyte injury (60) and cell proliferation in mesangial cells (61). It is possible that Smurf-1 is regulated by glucose uptake/metabolism by mechanisms similar to those of Gremlin-1, in which transforming growth factor $\beta$-1 (TGF $\beta-1)$ signaling pathways are amplified $(60,62)$. Indeed, dysregulated TGF $\beta$ - 1 signaling has been documented in pulmonary hypertension $(63,64)$, has opposing effects on BMP signaling $(65,66)$, and can up-regulate the expression of Smurf proteins $(67,68)$. More research is required to determine the links among glucose dysregulation, TGF $\beta-1$ signaling, and Smurf-1 expression in IPAH.

We could not determine Gremlin-1 protein expression from PASMCs, even though we found increased Gremlin-1 mRNA expression in the lung tissue and plasma of patients with IPAH (Figure 1), analogous to previous reports $(31,33)$. In addition, antibodies used to detect Gremlin-1 in the lung tissue by IHC were nonspecific in their staining and did not provide any measurable differences between IPAH and control PASMCs (data not shown). This could be because Gremlin-1 is expressed/induced more highly in other cell types such as endothelial or fibroblasts (which was not detectable by IHC) and may be involved more directly in BMP signaling downregulation in these cell types.

We put forth the notion that BMP signaling in IPAH may result from direct and indirect $B M P R 2$ mutation-independent mechanisms, both of which are influenced by glucose dysregulation (Figure 7). Directly, Gremlin-1 has been shown to bind with high affinity to BMPs (upstream), suppress their secretion (22), and block their actions in pulmonary circulation $(12,14,69)$. In addition, Gremlin-1 can influence lung tissue angiogenesis through directly antagonizing BMP (69) and has been shown to contribute to the development of PAH through hypoxia stimulation (31, 70). Gremlin-1, through glucose stimulation, may play a direct role in the pathogenesis or progression of IPAH. Indirectly, Smurf-1 has been shown to abrogate BMP signaling (downstream) through receptor- regulated Smad ubiquitination and proteasomal targeting (48), which is similar to our findings. Smurf-1 has also been shown to ubiquitin 
Control

$\frac{\text { PAH with BMPR2 }}{\text { mutation }}$
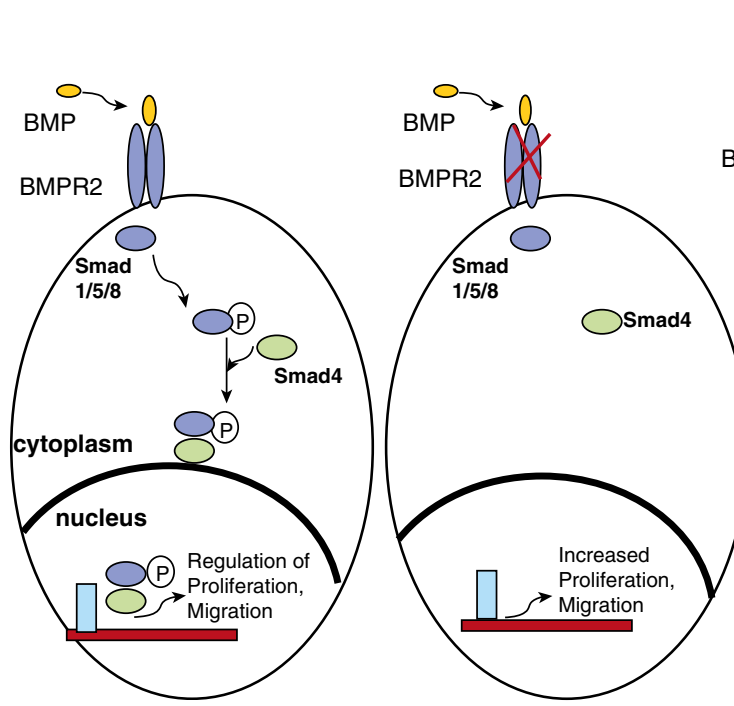

1)

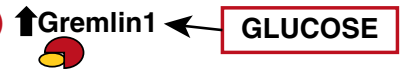

Figure 7. On increases in glucose levels, the BMP antagonists Gremlin-1 and Smurf-1 are stimulated and influence BMP signaling via bone morphogenic protein receptor (BMPR) mutation-independent mechanisms. By direct mechanisms, Gremlin-1 binds to BMPs and blocks the interaction of the ligand binding to the BMPR. Through an indirect mechanism, Smurf-1 binds to the receptor regulated Smads (Smads 1/5/8), which results in ubiquitin modification, and target these downstream BMP effector molecules for degradation. Consequently, these BMP antagonists may drive the increased PASMC proliferation that is characteristic in IPAH.

modify and target the BMPR2 for degradation in the lysosome in rats with monocrotalineand hypoxia-induced PAH (34). Smurf-1 may ubiquitin modify and target Smads for degradation, leading to BMPR2 instability and turnover in the lysosome. On the other hand, Smurf-1 may ubiquitinate the BMPR2 receptor, leading to its degradation and, in turn, trigger Smad protein ubiquitination and targeting for proteasomal degradation. Future work is required to determine the exact chronological steps involved in the mechanism(s) for BMPR2 instability and Smad degradation in IPAH. Nevertheless, the increase in Smurf-1 expression by the augmentation of glucose uptake/metabolism in IPAH results in a more active enzyme that influences the cell proliferation rate in PASMCs.

\section{Conclusions}

Our data show an indirect role for Smurf-1 down-regulation of BMP signaling through ubiquitination of the downstream Smad effector proteins. We show that Smurf-1 is regulated by glucose (Figure 5) and, on inhibition, results in decreased cell migration in the IPAH PASMCs, similar to control migration rates (Figure 6). Our findings suggest that blocking Smurf-1 (and/or Gremlin-1) levels may be a plausible therapeutic strategy to inhibit the effects of increased PASMC proliferation in IPAH. These data, together with the previously published reports, provide evidence for $B M P R 2$ mutation-independent mechanisms whereby glucose specifically influences Smurf-1 (and Gremlin-1) expression, resulting in altered BMP signaling in IPAH. Future work will focus on the intrinsic details of glucose stimulation in Smurf-1 and Gremlin-1 in IPAH and on potential therapeutic strategies to combat these BMP antagonists.

Author disclosures are available with the text of this article at www.atsjournals.org.

Acknowledgments: The authors thank the Cleveland Clinic Imaging and Histology Cores for the use of microscopes and services for histology experiments. Tissue samples were provided by the Pulmonary Hypertension Breakthrough Initiative.

\section{References}

1. Dweik RA, Rounds S, Erzurum SC, Archer S, Fagan K, Hassoun PM, Hill NS, Humbert M, Kawut SM, Krowka M, et al.; ATS Committee on Pulmonary Hypertension Phenotypes. An official American Thoracic Society Statement: pulmonary hypertension phenotypes. Am J Respir Crit Care Med 2014;189:345-355.

2. Tuder RM, Archer SL, Dorfmüller P, Erzurum SC, Guignabert C, Michelakis E, Rabinovitch M, Schermuly R, Stenmark KR, Morrell NW. Relevant issues in the pathology and pathobiology of pulmonary hypertension. J Am Coll Cardiol 2013; 62:D4-D12.

3. Ghamra ZW, Dweik RA. Primary pulmonary hypertension: an overview of epidemiology and pathogenesis. Cleve Clin J Med 2003;70:S2-S8.

4. The International Primary Pulmonary Hypertension Study (IPPHS). Chest 1994; 105:37S-41S.

5. Rubin LJ. Primary pulmonary hypertension. N Engl J Med 1997;336: 111-117.

6. Farber HW, Loscalzo J. Pulmonary arterial hypertension. $N$ Engl $J$ Med 2004;351:1655-1665.

7. Humbert M, Morrell NW, Archer SL, Stenmark KR, MacLean MR, Lang IM, Christman BW, Weir EK, Eickelberg O, Voelkel NF, et al. Cellular and molecular pathobiology of pulmonary arterial hypertension. J Am Coll Cardiol 2004; 43:13S-24S.
8. Kaneko FT, Arroliga AC, Dweik RA, Comhair SA, Laskowski D, Oppedisano R, Thomassen MJ, Erzurum SC. Biochemical reaction products of nitric oxide as quantitative markers of primary pulmonary hypertension. Am J Respir Crit Care Med 1998; 158:917-923.

9. Austin ED, Lahm T, West J, Tofovic SP, Johansen AK, Maclean MR, Alzoubi A, Oka M. Gender, sex hormones and pulmonary hypertension. Pulm Circ 2013;3:294-314.

10. Simonneau G, Robbins IM, Beghetti M, Channick RN, Delcroix M, Denton CP, Elliott CG, Gaine SP, Gladwin MT, Jing ZC, et al. Updated clinical classification of pulmonary hypertension. J Am Coll Cardiol 2009; 54:S43-S54.

11. Machado RD, Southgate L, Eichstaedt CA, Aldred MA, Austin ED, Best DH, Chung WK, Benjamin N, Elliott CG, Eyries M, et al. Pulmonary arterial hypertension: a current perspective on established and emerging molecular genetic defects. Hum Mutat 2015;36:1113-1127.

12. Anderson L, Lowery JW, Frank DB, Novitskaya T, Jones M, Mortlock DP, Chandler RL, de Caestecker MP. Bmp2 and Bmp4 exert opposing effects in hypoxic pulmonary hypertension. Am J Physiol Regul Integr Comp Physiol 2010;298:R833-R842.

13. Morty RE, Nejman B, Kwapiszewska G, Hecker M, Zakrzewicz A, Kouri FM, Peters DM, Dumitrascu R, Seeger W, Knaus P, et al. Dysregulated bone morphogenetic protein signaling in 
monocrotaline-induced pulmonary arterial hypertension. Arterioscler Thromb Vasc Biol 2007;27:1072-1078.

14. Frank DB, Abtahi A, Yamaguchi DJ, Manning S, Shyr Y, Pozzi A, Baldwin HS, Johnson JE, de Caestecker MP. Bone morphogenetic protein 4 promotes pulmonary vascular remodeling in hypoxic pulmonary hypertension. Circ Res 2005;97:496-504.

15. Song Y, Jones JE, Beppu H, Keaney JF Jr, Loscalzo J, Zhang YY. Increased susceptibility to pulmonary hypertension in heterozygous BMPR2-mutant mice. Circulation 2005;112:553-562.

16. Long L, Ormiston ML, Yang X, Southwood M, Gräf S, Machado RD, Mueller M, Kinzel B, Yung LM, Wilkinson JM, et al. Selective enhancement of endothelial BMPR-II with BMP9 reverses pulmonary arterial hypertension. Nat Med 2015;21:777-785.

17. Austin ED, Loyd JE. Heritable forms of pulmonary arterial hypertension. Semin Respir Crit Care Med 2013;34:568-580.

18. Larkin EK, Newman JH, Austin ED, Hemnes AR, Wheeler L, Robbins IM, West JD, Phillips JA III, Hamid R, Loyd JE. Longitudinal analysis casts doubt on the presence of genetic anticipation in heritable pulmonary arterial hypertension. Am J Respir Crit Care Med 2012; 186:892-896.

19. Yanagita M. BMP antagonists: their roles in development and involvement in pathophysiology. Cytokine Growth Factor Rev 2005; 16:309-317.

20. Rider CC, Mulloy B. Bone morphogenetic protein and growth differentiation factor cytokine families and their protein antagonists. Biochem J 2010;429:1-12.

21. Hsu DR, Economides AN, Wang X, Eimon PM, Harland RM. The Xenopus dorsalizing factor Gremlin identifies a novel family of secreted proteins that antagonize BMP activities. Mol Cell 1998;1:673-683.

22. Sun J, Zhuang FF, Mullersman JE, Chen H, Robertson EJ, Warburton D, Liu YH, Shi W. BMP4 activation and secretion are negatively regulated by an intracellular gremlin-BMP4 interaction. $J$ Biol Chem 2006;281:29349-29356.

23. Yue S, Tang LY, Tang Y, Tang Y, Shen QH, Ding J, Chen Y, Zhang Z, Yu TT, Zhang YE, et al. Requirement of Smurf-mediated endocytosis of Patched1 in sonic hedgehog signal reception. eLife 2014;3:3.

24. David D, Nair SA, Pillai MR. Smurf E3 ubiquitin ligases at the cross roads of oncogenesis and tumor suppression. Biochim Biophys Acta 2013;1835:119-128.

25. Khokha MK, Hsu D, Brunet LJ, Dionne MS, Harland RM. Gremlin is the BMP antagonist required for maintenance of Shh and Fgf signals during limb patterning. Nat Genet 2003;34:303-307.

26. Michos O, Panman L, Vintersten K, Beier K, Zeller R, Zuniga A. Gremlin-mediated BMP antagonism induces the epithelialmesenchymal feedback signaling controlling metanephric kidney and limb organogenesis. Development 2004;131:3401-3410.

27. Lu MM, Yang H, Zhang L, Shu W, Blair DG, Morrisey EE. The bone morphogenic protein antagonist gremlin regulates proximal-distal patterning of the lung. Dev Dyn 2001;222:667-680.

28. Costello CM, Cahill E, Martin F, Gaine S, McLoughlin P. Role of gremlin in the lung: development and disease. Am J Respir Cell Mol Biol 2010;42:517-523.

29. Zhang Y, Zhang Q. Bone morphogenetic protein-7 and Gremlin: new emerging therapeutic targets for diabetic nephropathy. Biochem Biophys Res Commun 2009;383:1-3.

30. Walsh DW, Godson C, Brazil DP, Martin F. Extracellular BMP-antagonist regulation in development and disease: tied up in knots. Trends Cell Biol 2010;20:244-256.

31. Cahill E, Costello CM, Rowan SC, Harkin S, Howell K, Leonard MO, Southwood M, Cummins EP, Fitzpatrick SF, Taylor CT, et al. Gremlin plays a key role in the pathogenesis of pulmonary hypertension. Circulation 2012;125:920-930.

32. Ciuclan L, Sheppard K, Dong L, Sutton D, Duggan N, Hussey M, Simmons J, Morrell NW, Jarai G, Edwards M, et al. Treatment with anti-gremlin 1 antibody ameliorates chronic hypoxia/SU5416induced pulmonary arterial hypertension in mice. Am J Pathol 2013; 183:1461-1473.

33. Wellbrock J, Harbaum L, Stamm H, Hennigs JK, Schulz B, Klose H, Bokemeyer C, Fiedler W, Lüneburg N. Intrinsic BMP antagonist Gremlin-1 as a novel circulating marker in pulmonary arterial hypertension. Lung 2015;193:567-570.
34. Murakami K, Mathew R, Huang J, Farahani R, Peng H, Olson SC, Etlinger JD. Smurf1 ubiquitin ligase causes downregulation of BMP receptors and is induced in monocrotaline and hypoxia models of pulmonary arterial hypertension. Exp Biol Med (Maywood) 2010;235: 805-813.

35. Marsboom G, Wietholt C, Haney CR, Toth PT, Ryan JJ, Morrow E, Thenappan T, Bache-Wiig P, Piao L, Paul J, et al. Lung ${ }^{18} \mathrm{~F}$-fluorodeoxyglucose positron emission tomography for diagnosis and monitoring of pulmonary arterial hypertension. Am J Respir Crit Care Med 2012;185:670-679.

36. Piao L, Fang YH, Cadete VJ, Wietholt C, Urboniene D, Toth PT, Marsboom G, Zhang HJ, Haber I, Rehman J, et al. The inhibition of pyruvate dehydrogenase kinase improves impaired cardiac function and electrical remodeling in two models of right ventricular hypertrophy: resuscitating the hibernating right ventricle. $\mathrm{J} \mathrm{Mol} \mathrm{Med}$ (Berl) 2010;88:47-60.

37. Paulin R, Michelakis ED. The metabolic theory of pulmonary arterial hypertension. Circ Res 2014;115:148-164.

38. Barnes JW, Tian L, Heresi GA, Farver CF, Asosingh K, Comhair SA Aulak KS, Dweik RA. O-linked $\beta$-N-acetylglucosamine transferase directs cell proliferation in idiopathic pulmonary arterial hypertension. Circulation 2015;131:1260-1268.

39. Barnes J, Dweik RA. Is pulmonary hypertension a metabolic disease? Am J Respir Crit Care Med 2014;190:973-975.

40. Comhair SA, Xu W, Mavrakis L, Aldred MA, Asosingh K, Erzurum SC. Human primary lung endothelial cells in culture. Am J Respir Cell Mol Biol 2012;46:723-730.

41. Asosingh K, Aldred MA, Vasanji A, Drazba J, Sharp J, Farver C, Comhair SA, Xu W, Licina L, Huang L, et al. Circulating angiogenic precursors in idiopathic pulmonary arterial hypertension. Am J Pathol 2008;172:615-627.

42. Aldred MA, Vijayakrishnan J, James V, Soubrier F, Gomez-Sanchez MA, Martensson G, Galie N, Manes A, Corris P, Simonneau G, et al. BMPR2 gene rearrangements account for a significant proportion of mutations in familial and idiopathic pulmonary arterial hypertension. Hum Mutat 2006;27:212-213.

43. Schmittgen TD, Livak KJ. Analyzing real-time PCR data by the comparative $\mathrm{C}_{\mathrm{T}}$ method. Nat Protoc 2008;3:1101-1108.

44. Schneider CA, Rasband WS, Eliceiri KW. NIH Image to ImageJ: 25 years of image analysis. Nat Methods 2012;9:671-675.

45. Zhang L, Zhou F, van Dinther M, Ten Dijke P. Determining TGF- $\beta$ receptor levels in the cell membrane. Methods Mol Biol 2016;1344:35-47.

46. Zhao K, Shi YB. An anti-cancer Smurf. Cell Biosci 2012;2:10.

47. Cao Y, Zhang L. A Smurf1 tale: function and regulation of an ubiquitin ligase in multiple cellular networks. Cell Mol Life Sci 2013;70: 2305-2317.

48. Zhu H, Kavsak P, Abdollah S, Wrana JL, Thomsen GH. A SMAD ubiquitin ligase targets the BMP pathway and affects embryonic pattern formation. Nature 1999;400:687-693.

49. Marín I. Animal HECT ubiquitin ligases: evolution and functional implications. BMC Evol Biol 2010;10:56.

50. Xu W, Koeck T, Lara AR, Neumann D, DiFilippo FP, Koo M, Janocha AJ, Masri FA, Arroliga AC, Jennings C, et al. Alterations of cellular bioenergetics in pulmonary artery endothelial cells. Proc Natl Acad Sci USA 2007;104:1342-1347.

51. Cao Y, Wang C, Zhang X, Xing G, Lu K, Gu Y, He F, Zhang L. Selective small molecule compounds increase BMP-2 responsiveness by inhibiting Smurf1-mediated Smad1/5 degradation. Sci Rep 2014;4: 4965.

52. Ali IH, Brazil DP. Bone morphogenetic proteins and their antagonists: current and emerging clinical uses. Br J Pharmacol 2014;171: 3620-3632.

53. Brazil DP, Church RH, Surae S, Godson C, Martin F. BMP signalling: agony and antagony in the family. Trends Cell Biol 2015;25: 249-264.

54. Karagiannis GS, Musrap N, Saraon P, Treacy A, Schaeffer DF, Kirsch $\mathrm{R}$, Riddell RH, Diamandis EP. Bone morphogenetic protein antagonist gremlin-1 regulates colon cancer progression. Biol Chem 2015;396:163-183.

55. Sneddon JB, Zhen HH, Montgomery K, van de Rijn M, Tward AD, West R, Gladstone $\mathrm{H}$, Chang HY, Morganroth GS, Oro AE, et al. Bone morphogenetic protein antagonist gremlin 1 is widely 
expressed by cancer-associated stromal cells and can promote tumor cell proliferation. Proc Natl Acad Sci USA 2006;103: 14842-14847.

56. Ryan JJ, Archer SL. The right ventricle in pulmonary arterial hypertension: disorders of metabolism, angiogenesis and adrenergic signaling in right ventricular failure. Circ Res 2014;115:176-188.

57. Piao L, Fang YH, Parikh K, Ryan JJ, Toth PT, Archer SL. Cardiac glutaminolysis: a maladaptive cancer metabolism pathway in the right ventricle in pulmonary hypertension. $J$ Mol Med (Berl) 2013;91: 1185-1197.

58. McMahon R, Murphy M, Clarkson M, Taal M, Mackenzie HS, Godson C, Martin F, Brady HR. IHG-2, a mesangial cell gene induced by high glucose, is human gremlin. Regulation by extracellular glucose concentration, cyclic mechanical strain, and transforming growth factor- $\beta 1$. J Biol Chem 2000;275:9901-9904.

59. Lee JO, Lee SK, Kim N, Kim JH, You GY, Moon JW, Jie S, Kim SJ, Lee YW, Kang HJ, et al. E3 ubiquitin ligase, WWP1, interacts with AMPK $\alpha 2$ and down-regulates its expression in skeletal muscle C2C12 cells. J Biol Chem 2013;288:4673-4680.

60. Li G, Li Y, Liu S, Shi Y, Chi Y, Liu G, Shan T. Gremlin aggravates hyperglycemia-induced podocyte injury by a TGF $\beta / S$ mad dependent signaling pathway. J Cell Biochem 2013;114:2101-2113.

61. Huang $\mathrm{H}$, Huang H, Li Y, Liu M, Shi Y, Chi Y, Zhang T. Gremlin induces cell proliferation and extra cellular matrix accumulation in mouse mesangial cells exposed to high glucose via the ERK1/2 pathway. BMC Nephrol 2013;14:33.

62. Zhang H, Cui YC, Li K, Yang BQ, Liu XP, Zhang D, Li H, Wu AL, Tang Y. Glutamine protects cardiomyocytes from hypoxia/reoxygenation injury under high glucose conditions through inhibition of the transforming growth factor- $\beta 1-S m a d 3$ pathway. Arch Biochem Biophys 2016;596:43-50.
63. Yuan W, Liu W, Cai H, Sun X, Yang D, Xu F, Jin C. SB-431542, a specific inhibitor of the TGF- $\beta$ type I receptor inhibits hypoxiainduced proliferation of pulmonary artery adventitial fibroblasts. Pharmazie 2016;71:94-100.

64. Wang XB, Wang W, Zhu XC, Ye WJ, Cai H, Wu PL, Huang XY, Wang $L X$. The potential of asiaticoside for TGF- $\beta 1 /$ Smad signaling inhibition in prevention and progression of hypoxia-induced pulmonary hypertension. Life Sci 2015;137:56-64.

65. Zhao L, Yee M, O'Reilly MA. Transdifferentiation of alveolar epithelial type II to type I cells is controlled by opposing TGF- $\beta$ and BMP signaling. Am J Physiol Lung Cell Mol Physiol 2013;305: L409-L418.

66. Stumm CL, Halcsik E, Landgraf RG, Camara NO, Sogayar MC, Jancar S. Lung remodeling in a mouse model of asthma involves a balance between TGF- $\beta 1$ and BMP-7. PLoS One 2014;9: e95959.

67. Yu L, Liu X, Cui K, Di Y, Xin L, Sun X, Zhang W, Yang X, Wei M, Yao Z, et al. SND1 acts downstream of TGF $\beta 1$ and upstream of Smurf1 to promote breast cancer metastasis. Cancer Res 2015;75: $1275-1286$

68. Fu X, Song B, Tian GW, Li JL. The effects of the water-extraction of Astragali Radix and Lycopi herba on the pathway of TGF-Smads-UPP in a rat model of diabetic nephropathy. Pharmacogn Mag 2014;10:491-496.

69. Stabile H, Mitola S, Moroni E, Belleri M, Nicoli S, Coltrini D, Peri F, Pessi A, Orsatti L, Talamo F, et al. Bone morphogenic protein antagonist Drm/gremlin is a novel proangiogenic factor. Blood 2007;109: $1834-1840$.

70. Maciel TT, Melo RS, Schor N, Campos AH. Gremlin promotes vascular smooth muscle cell proliferation and migration. J Mol Cell Cardiol 2008;44:370-379. 